\title{
Alternative medicine and the medical profession: views of medical students and general practitioners
}

M.Y. Hasan, ${ }^{\top}$ M. Das ${ }^{2}$ and S. Behjat ${ }^{3}$

$$
\begin{aligned}
& \text { الطب البديل ومهنة الطب: آراء طلاب الطب والمبارسين العامين }
\end{aligned}
$$

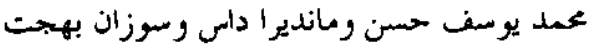

نحلامسة: أتمري اسمتقعاء بهدف استكثاف مواتف المهارسين العامين وطلاب الطب في الإمارات العربية المتحسدة

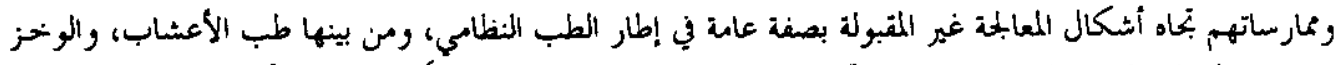

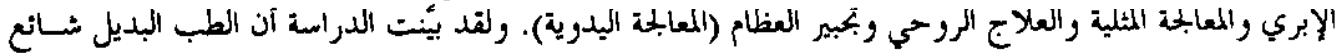

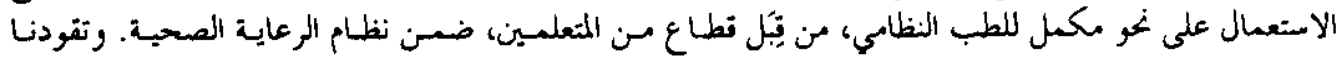

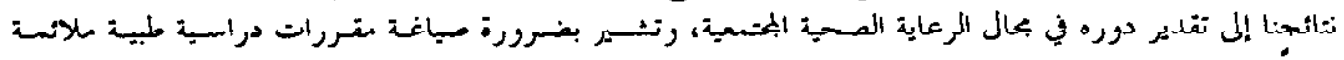

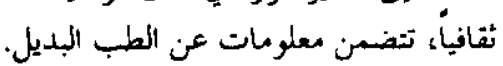

ABSTRACT A survey was undertaken to explore the attitudes and practices of general practitioners and medical students in the United Arab Emirates with regards to forms of therapy not generally accepted by conventional medicine, including herbal medicine, acupuncture, homeopathy, spiritual therapy and ostoopathy/chiropractic. The study found that alternative medicine is in common use to complement conventional medicine by a section of educated people within the health care system. Our observations lead us to appreciate its role in community health care and indicate a need to design culturally appropriate medical curricula which incorporate information about alternative medicine.

La médecine alternative et la profession médicale: opinions des médecins généralistes et des etudiants de medecine

RESUME Une enquête a été réalisée pour examiner les attitudes et les pratiques des médecins généralistes et des étudiants de médecine aux Emirats arabes unis en ce qui concerne les formes de traitement qui ne sont généralement pas accoptéos par la médocine classique, notamment la phytothérapie, l'acupuncture, l'homéopathie, la thérapie spirituelle et l'ostéopathie/la chiropraxie. L'étude a révélé que la médecine alternative est couramment utilisée en complément de la médecine classique par un groupe de personnes instruites dans le systeme de soins de santé. Nos observations nous ont amené à apprécier son rôle dans les soins de santé communautaires et montrent la nécessité de concevoir des programmes d'enseignement médical adaptés sur le plan culturel qui comportent des informations concernant la médecine alternative.

'Department of Pharmacology; ${ }^{2}$ Department of Medical Education, Faculty of Medicine and Health Sciences, United Arab Emirates University, Al-Ain, United Arab Emirates.

IInternational Health Department. Ministry of Health. Abu Dhabi. United Arab Emirates.

Aeceived: 14/06/98; accepted: 18/10/98 


\section{Introduction}

Alternative medicine is broadly defined as any medical practice that does not conform to the standards of the medical community and its conventional practice of medicine. It is also referred to as unconventional, unorthodox, complementary or traditional medicine. The use of different types of alternative medicine varies from place to place, but some common examples are herbal medicine, acupuncture, homeopathy, osteopathy, chiropractic, reflexology, aromatherapy, naturopathy, commercial weight-loss programmes and spiritual healing $[1,2]$.

A high level of interest in and acceptance of alternative medicine among general practitioners (GPs) has becn reported in recent years $[1,3-6]$. There are several reasons for such impressions:

- There has been frequent use of alternative medicine in the recent past and this trend is not confined to any particular part of the world [7-9].

- An important cause of non-compliance in modern medicine is the availability and use of alternative medicine. $\mathrm{Pa}$ tients often hesitate to disclose this information to physicians, fearing disapproval, which leads to poor doctorpatient relationships [10-12].

- The estimated expenditure associated with the use of alternative therapy in the United States of America in 1990 was comparable to the amount spent for all hospitalizations there [2].

- With the increase in cost of conventional medical treatment, the incidence of selfmedication has increased and many families prefer to try home remedies and alternative therapies before consulting a qualified medical practitioner [12].

- Many physicians believe in the usefulness of alternative medicine, especially in cases where conventional medicine cannot provide a cure. Often there seems to be no effective therapy for chronic back or joint pain, cancer, depression, gastrointestinal and liver disorders, skin problems or diseases categorized as "allergic" or "autoimmune" [2].

- Alternative medicine is no longer thought to be harmless. Many studies warn about the possible dangers of using alternative medicine. For example, it has been reported that the use of ginseng, a traditional Chinese herb, has caused intoxication requiring clinical attention [13].

For many centuries alternative medicine has been the main form of treatment in Asian countries, including the Arabian peninsula. Ayurveda, from the ancient Vedic culture of India, was in practice before 4000 BC. Traditional Chinese medicine has a history of more than 4000 years. In the Middle East, the first written records detailing the use of herbs in the treatment of illness are Mesopotamian clay tablet writings and Egyptian papyrus. In the Arabian peninsula, a common form of alternative medicine known as unani combines various elements of centuries-old Arabic practices. These traditional practices of healing have gone through several stages of development over the centuries and traditional medicines are still the backbone of medicine in many Asian countries.

Despite the fact that for years traditional practices received relatively little support from national and international health organizations, they have survived and their presence and influence on health care systems have been recognized. As part of its Global Strategy for Health for All in the 21 st Century, the World Health Organization (WHO) has supported the integration of conventional and alternative medicine to 
improve the quality of health care. WHO has taken a leadership role in the development of related policies [14] and facilitated the exchange of information. WHO has convened several meetings since the early seventies on the promotion and development of alternative medicine to help foster a realistic approach to incorporating it into primary health care systems

Although studies are available that indicate a high degree of interest in alternative medicine among both physicians and residents, the attitudes of medical students have not been adequately explored. With the sudden economic development of member countries of the Gulf Cooperation Council in recent years, high quality, modern treatment has become easily available, but our earlier study has shown that this has not changed patient behaviour [15]. In fact, all 64 families interviewed for that study indicated extensive use of alternative therapies. Even first-year medical students at the United Arab Emirates (UAE) University reported that they had used some form of alternative medicine [15].

Although most physicians currently working in the UAE are expatriates, UAE University only admits medical students who are UAE nationals with the expectation that these students will replace the expatriates and take over the role of providing health care to the people of their country. This study was designed to assess the perceptions of both the physicians and the medical students towards alternative medicine. The data obtained will be of use in designing undergraduate and postgraduate educational programmes to improve the existing health care system.

\section{Materials and methods}

GPs from primary health care (PHC) centres and government hospitals in three main
UAE cities, Abu Dhabi, Sharjah and Al-Ain, were chosen for the study. Dubai, another major cily, was excluded because it has a separate health care system. The communities in the three cities include both locals and expatriates. At the time of the study, the total number of GPs employed in the PHC centres and government hospitals in these cities was 1140. Most of the GPs were expatriates and all had obtained their medical training outside the UAE. A total of 300 GPs from 87 PHC centres and 7 hospitals were randomly selected for inclusion in the study.

The study also included 136 medical students, all of whom were UAE nationals, in their first through fourth years of study at the raculty of Medicine and Health Sciences, UAE University, Al-Ain. All of the students had attended a 12-hour programme on alternative medicine during the first year of the medical curriculum. The programme consisted of a visit to the herbal centre at Abu Dhabi and discussions with qualitied alternative medicine practitioners and faculty members of the Faculty of Medicine and Health Sciences [15].

\section{Data collection}

A structured, self-administered questionnaire was used as the study instrument. Alternative medical systems and techniques were grouped according to definitions made by the UAE Ministry of Health and only techniques and therapies which can be legally practised in the UAE, including herbal medicine, acupuncture, homeopathy, spiritual therapy and osteopathy/chiropractic, were included.

The questionnaire consisted of 15 direct questions on the use of and attitudes towards alternative medicine and the incorporation of alternative medicine into the UAE health care system. The questions also dealt with awareness of the availabili- 
ty, effectiveness and possible harmful effects of alternative medicine. The GPs were also asked if they took a history of their patients' use of alternative medicine or referred them to qualified alternative medicine practitioners. If they had referred patients, they were asked to name the medical conditions for which they referred the patients and also the method of referral (i.c. verbal or written recommendation).

The questionnaires were distributed simultancously by mail to all GPs. Prestamped envelopes with the return address were provided to ensure anonymous return. Questionnaires were distributed to all medical students by hand. The students were requested to return the completed forms to any of the authors.

\section{Statistical analysis}

The data were analysed using SPSS. The frequency distributions were obtained and the chi-squared test was used to ascertain significant differences between the data of the students and of the GPs. The level of $P$ $<0.05$ was the cut-off value for significant difference.

\section{Results}

\section{Demographic characteristics of the respondents}

Of the 300 GPs included, $158(52.7 \%)$ responded. Of these, $67(42.4 \%)$ were women and $91(57.6 \%)$ were men. Of the respondent GPs, $90(57.0 \%)$ were in the $35-44$-year age group, $46(29.1 \%)$ were in the 45-54-year age group, 20 (12.7\%) werc in the 25-34-year age group and $2(1.3 \%)$ were over 55 years of age. Sharjah GPs had a $65 \%$ response rate, Abu Dhabi GPs $42 \%$ and $\mathrm{Al}$-Ain GPs $43 \%$. Most of the respondent GPs (67.1\%) worked in PHC centres and the remainder in hospitals. GPs from
Arab countries other than the UAE accounted for $46.8 \%$ of the respondent GPs, $27.2 \%$ werc from Asian countries, $7 \%$ were from European countries, $8.9 \%$ were UAE nationals and the remainder were categorized as "other". Of the respondent GPs, $55 \%$ had postgraduate degrees/fellowships, while the rest were medical graduates without further qualifications. Although many of the GPs had attended seminars or had engaged in self-education on alternative medicine, none of them had any formal training in alternative medicine.

Of the 136 participating students, 113 $(83 \%)$ responded. Of these, all were within the age group 18-24 years and $85(75.2 \%)$ were women, while $28(24.8 \%)$ were men.

\section{Use of alternative medicine}

The results showed widespread use of alternative medicine among students, GPs, and their friends and relatives (Table 1). Almost $73 \%$ of the students indicated personal use of herbal medicine and $76 \%$ reported use by a friend or relative. The use of other therapies was also reported, but to a lesser extent. Although the students were much younger than the GPs, they were found to have had more experience using herbal medicine, spiritual therapy and osteopathy/ chiropractic than the GPs $(P<0.001)$. Also, more students than GPs reported that they would consider using these therapies $(P<$ 0.001 ).

\section{Effectiveness and harmful effects of alternative medicine}

In spite of extensive use, many students and GPs were unsure of the effectiveness of alternative medicine (Table 2). However, more GPs than students considered herbal medicine, acupuncture and homeopathy to be effective $(P<0.005)$, while more students than GPs considered spiritual therapy and osteopathy/chiropractic to be effective 


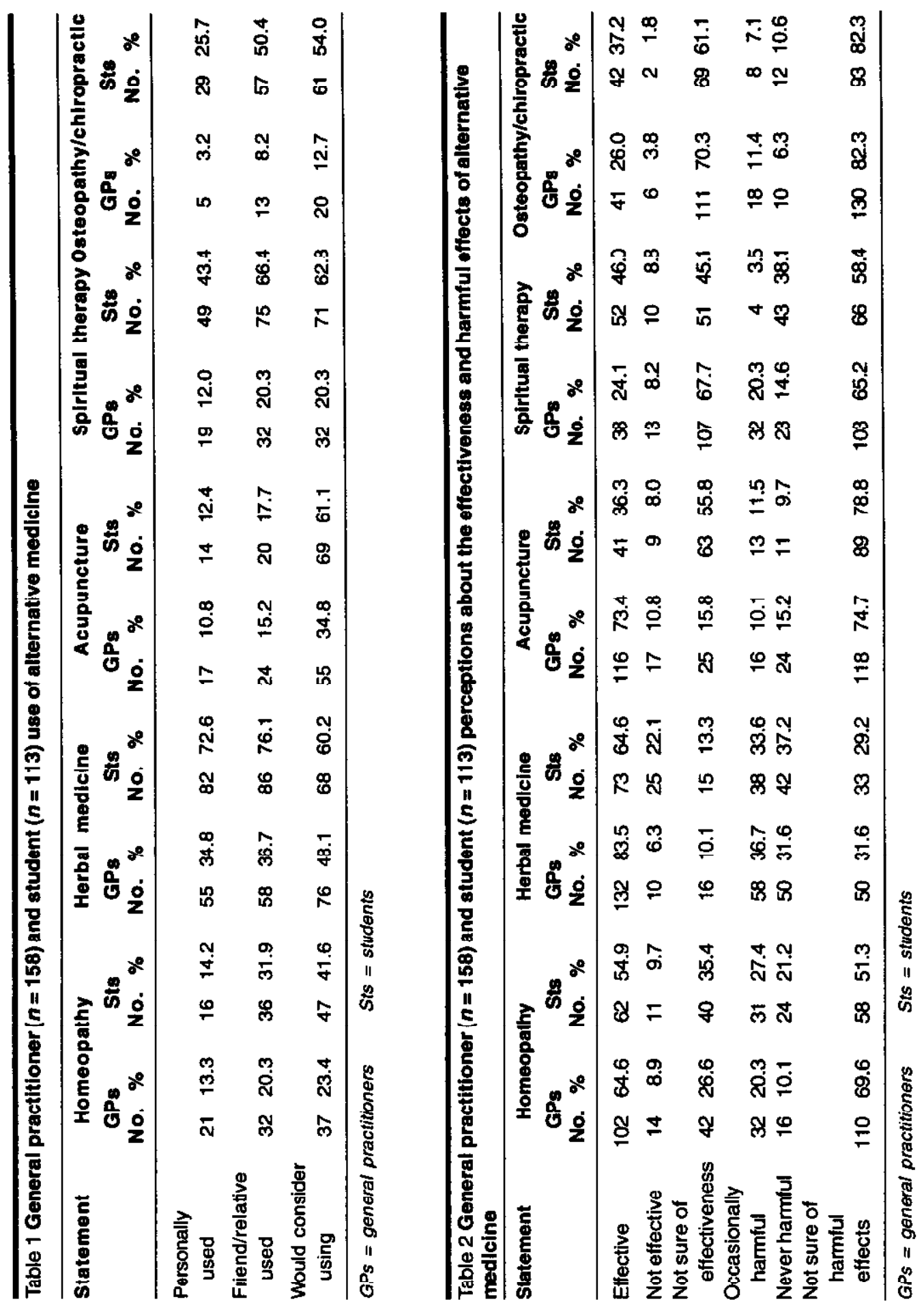


$(P<0.001)$. The perceptions of the GPs and students about the harmful effects of many alternative therapies were similar, but fewer students considered spiritual therapy to be harmful, which was significantly different from the opinion of the GPs $(P<$ 0.001 ).

\section{Attitudes towards alternative medicine}

Although the majority of GPs (69\%) believed that they should know about herbal medicine, they were divided with regards to homeopathy and acupuncture (Table 3). Most of them did not see a need to know about spiritual therapy nor osteopathy/chiropractic. This was in contrast to the students' opinions $(P<0.001)$. Very few of the GPs or students had read articles or attended educational sessions on forms of alternative therapy other than herbal medicine A great majority of both the GPs and students believed that herbal therapists should be allowed to practise in the UAF and more than half believed that acupuncture should be allowed. However, few GPs supported the practice of osteopathy/ chiropractic. Although all but two of the students believed that it was important, more than a quarter of the GPs did not take a history of their patients' use of alternative medicine $(P<$ $0.001)$. Nearly $70 \%$ of the students and $38.6 \%$ of the GPs $(P<0.001)$ said they knew herbal practitioners, but few GPs or students knew any other alternative practitioners.

\section{Referrals}

An overwhelming majority of students, 99 out of $113(87.6 \%)$, reported that they would consider referring

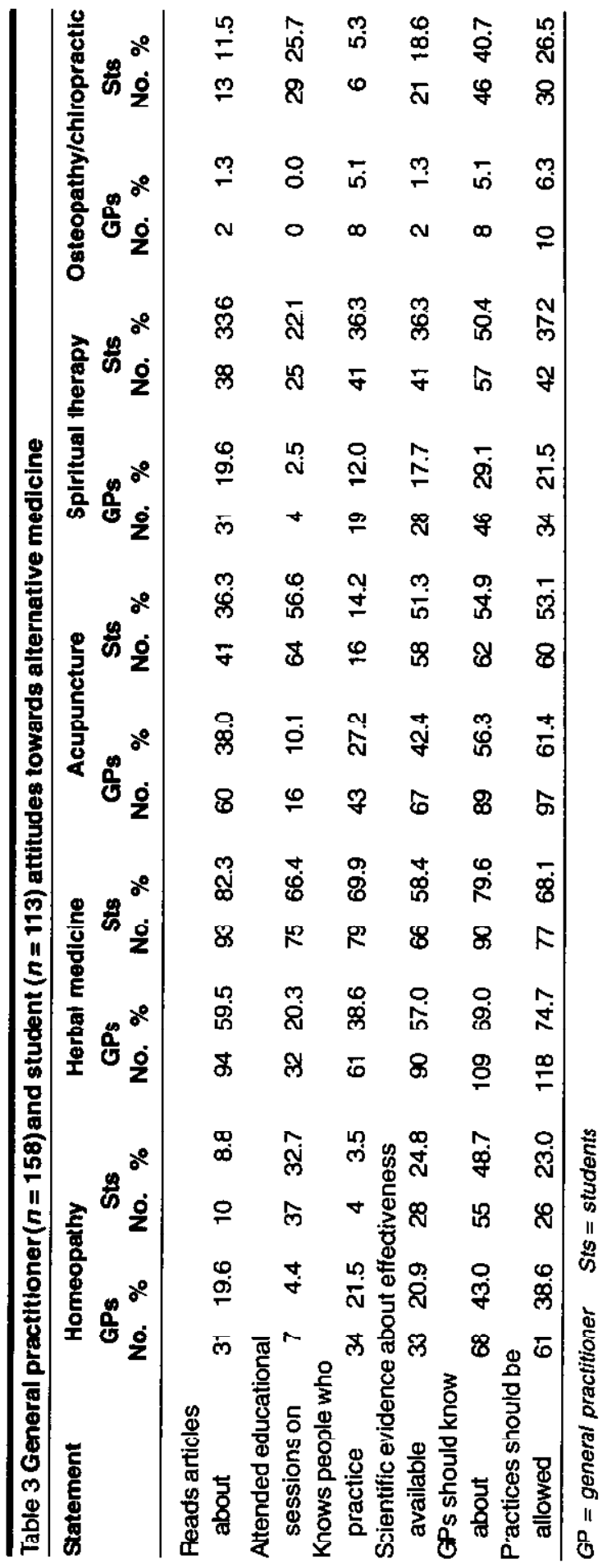


Table 4 GPs who referred patients to alternative medicine practitioners in the past year and students who would consider referring patients

\begin{tabular}{lrrrr}
\hline $\begin{array}{l}\text { Alternative } \\
\text { medicine }\end{array}$ & \multicolumn{2}{c}{ GPs } & \multicolumn{2}{c}{ Students } \\
& No. & \multicolumn{1}{c}{$\%$} & \multicolumn{2}{c}{$(n=113)$} \\
& No. & $\%$ \\
\hline Herbal medicine & 50 & 31.6 & 99 & 87.6 \\
Acupuncture & 26 & 16.5 & 72 & 63.7 \\
Spiritual therapy & 14 & 8.9 & 59 & 52.2 \\
Osteopathy & & & & \\
/chiropractic & 4 & 2.5 & 58 & 51.3 \\
Homeopathy & 15 & 9.5 & 41 & 36.3 \\
\hline
\end{tabular}

$G P=$ general practitioner

patients for herbal medicine. Acupuncture would be considered by $72(63.7 \%)$, spiritual therapy by $59(52.2 \%)$ and osteopathy/ chiropractic by $58(51.3 \%)$, showing sizeable support for these practices among the students. Even homeopathy, which was lowest in popularity, would be considered by $41(36.3 \%)$ of the students.

Although as many as 50 GPs $(31.6 \%)$ had referred patients to a herbal medicine specialist, few had referred patients to specialists of other forms of alternative medicine: acupuncture, 26 (16.5\%); spiritual therapy, $14(8.9 \%)$; osteopathy/chiropractic, $4(2.5 \%)$; and homeopathy, $15(9.5 \%)$. The conditions for which patients were referred were chronic ailments, such as asthma, diabetes mellitus, hypertension, cancer and skin disorders, and a variety of nonspecific disorders, including headache, backache, joint pain, fainting, gastric troubles and depression. All referrals made by the GPs were verbal. As many as $24 \%$ of the GPs had prescribed herbal medicine themselves and $7 \%$ had advised spiritual therapy.

\section{Discussion}

The results of the study indicate that alternative medicine has an enormous hidden presence and influence within the health care system of the UAE. Although the GPs' knowledge about various forms of alternative medicine was limited, they did not dismiss such practices as mere quackery, a finding that is supported by the number of study participants who had themselves used, or knew people who had used, alternative medicine. The fact that a fairly large number of the GPs even suggested patients approach practitioners of alternative medicine shows that GPs not only acknowledge the existence of unconventional therapies, but also support them, even if they are viewed as a last resort. A comparison with published data indicates that disorders for which UAE GPs refer patients to alternative therapies are ones for which such therapies are also in frequent use elsewhere in the world $[1,2]$.

Our results further indicate that not all forms of alternative therapies share a similar level of acceptance by the GPs. Many of them suggested that herbal medicine, homeopathy and acupuncture were effective and should be allowed in the UAE, but they were less sure about the effectiveness of spiritual therapy and osteopathy/chiropractic and did not support their practice in the UAE. Our findings demonstrate that the perceptions of UAE GPs differ from those in the United Kingdom [3] and the Netherlands [5], where a majority of GPs considered spinal manipulation useful and referred patients to osteopathy/chiropractic practitioners. GPs in these countries also referred many patients for hypnosis, acupuncture and homeopathy. Such geographical difference in the choice of alternative therapies among GPs is significant and indicates the need for regional studies before

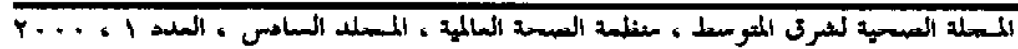


designing educational programmes and making decisions about the reform of health care systems.

Our observation that a majority of UAE GPs do discuss the use of alternative medicine is similar to reports that GPs in some European countries also discuss and, on occasion, actually endorse alternative medicine in their patient encounters $[6,16]$. Discussing the preferred type of care with the patient and suggesting suitable alternative therapies helps improve patient-doctor relations.

The differences in opinion between students and GPs in the UAE is of note. The students seem to be better informed, more open to new ideas, and aware of the need for collaboration between practitioners of conventional and alternative therapies to develop a more congenial atmosphere. The students were all younger, UJAF nationals and had been educated in the UAE. Most of them had used alternative therapies for treatment of their own ailments and were aware of many others using them and thus had knowledge of the results of such treatment. In addition, they had also had a short introductory course in the first year of the medical curriculum.

With the exception of herbal medicine, the GPs and students also differed on which types of alternative medicine they would refer patients for. More students would refer patients for homeopathy, spiritual therapy and osteopathy/chiropractic than the
GPs. Such differences in opinion have important implications as today's students will be tomorrow's physicians.

The results of our study suggest that information about alternative medicine should be provided to both medical students and GPs. Teaching and learning methods need to be developed and teachers willing to participate in such programmes need to be identified. Qualified practitioners of alternative medicine should be included in the team so that they can share their knowledge and skills with students and GPs and develop mutual understanding. The involvement of qualified practitioners of alternative medicine will also help the participants to assess each other's strengths, limitations and practice patterns and provide an opportunity to discuss solutions for individual and community health prohlems. This will also reduce misunderstandings and resistance between so-called conventional and unconventional therapists. Communication hetween students, doctors and practitioners of alternative medicine will promote research in neglected areas and further develon health care providers' ability to deal with uncertainties.

\section{Acknowledgement}

The authors thank Mr Suhrid Manchanda for technical and editorial assistance.

\section{References}

1. Reilly DT. Young doctors' views on alternative medicine. British medical joumal, 1983, 287(6388):337-9.

2 Eisenberg DM et al. Unconventional modicino in tho Unitod Statoc. Prova- lence, costs and patterns of use. New Enoland journal of medicine. 1993. 328(4):246-52.

3. Wharton $\mathbf{R}$, Lewith $\mathrm{G}$. Complementary modioine and the genoral praotitioner. 
British medical journal, 1986, 292:1498-500.

5. Vlsser GJ, Peters L. Alternative medicine and general practitioners in the Netherlands: towards acceptance and integration. Family practice, 1990, 7(3):227-32.

6. Borkan $\mathrm{J}$ et al. Referrals for alternative therapies. Journal of family practice, 1994, 4. Cherkin D, MacCornack FA, Berg AO. Family physicians' views of chiropractors: hostile or hospitable? American journal of public health, 1989, 79(5):636-7.39(6):545-50.

7. Akerele $O$. The best of both worlds: bringing traditional medicine up to date. Social science and medicine, 1987, 24:177-81.

8. Eisenbruch $M$. Medical education for a multicultural society. Medical journal of Australia, 1989, 151(10):574-80.

9. Kraut AM. Healers and strangers. Immigrant attitudes toward the physician in America - a relationship in historical perspective. Journal of the American Medical Association, 1990, 263:180711.

10. Murray J, Shepherd S. Alternativo or ad. ditional medicine? A new dilemma for the doctor. Journal of the Royal College of General Practitioners, 1988, 38(316): 511-4.

11. Rankin SB, Kappy MS. Developing therapeutic relationships in multicultural sottings. Academic medicine, 1993, 68(11):826-7.

12. Lam $\mathrm{CL}$ et al. Self-medication among Hong Kong Chlnese. Soclal science and medicine, 1994, 39(12):1641-7.

13. Siegel RK. Ginseng abuse syndrome: problems with the panacea. Journal of the American Medical Association, 1979, 241(15):1614-5.

14. Regulatory situation of herbal medicines: a worldwide review. Geneva, World Health Organization, 1998.

15. Das M, Hasan MY, Murdoch CM. An introductory program to alternative medicine in the undergraduate medical curriculum. Teaching and learning in medicine, 1997, 10:222-8.

16. Fulder SJ, Munro RE. Complementary medicine in the United Kingdom: patients, practitioners and consultations. Lancot, 1985, 2(8454):542-5. 